\title{
The Diabetes Education Experience of Randomly Selected Patients Under the Care of Community Physicians
}

\author{
ROBERT M. ANDERSON, EdD; ROLAND G. HISS, MD; CATHIE J. STEPIEN, MPH, RN; \\ JAMES T. FITZGERALD, PhD; MARTHA M. FUNNELL, MS, RN, CDE
}

The purpose of this study was to describe the diabetes education and nutritional counseling received by patients under the active care of community physicians. The study population consisted of 440 patients with diabetes from the practices of 68 primary care physicians in eight Michigan communities. Fifty-eight percent of the sample reported having received diabetes education, and the mean number of years since the most recent education was 4.15 years. Sixty-six percent reported having seen a dietitian. Patients who had received diabetes education scored higher on a basic diabetes knowledge test (70\% correct vs $60 \%$ ) than patients who had not received diabetes education. From 1981 to 1991, a decline was observed in the percentage of patients who reported having received diabetes education (70\% to $58 \%$ ). Although patient education is an integral part of comprehensive diabetes care, too few patients are receiving it. Furthermore, diabetes education often results in less-than-optimal levels of knowledge. The situation has deteriorated over the past 10 years, and patients who are not on insulin typically are the least well served.
The publication Healthy People 2000 describes diabetes patient education as "an integral aspect of patient management and a mainstay of patient self-care."' As further evidence of the essential nature of patient education in diabetes care, the American Diabetes Association's (ADA) standards of medical care include patient and family education as part of the management plan and emphasize the importance of the patient understanding each aspect of the plan. ${ }^{2}$ The standards also call for individualized nutrition instruction, preferably by a dietitian. A review of knowledge and self-care skills is recommended at least annually.

The effectiveness of various teaching methodologies and specific educational programs has been studied extensively. In reported meta-analyses of educational and psychosocial interventions, ${ }^{3.5}$ patient education has been found to be effective in improving knowledge, skills, psychosocial adjustment, and metabolic control. While diabetes education is considered an effective and essential component of the care of patients with diabetes, not all people with diabetes attend educational programs or receive teaching about their illness beyond their physician visits. In a 1984 Michigan household survey, ${ }^{6}$ only $68 \%$ of the respondents with diabetes had received instruction or counseling about diabetes, and only $32 \%$ had attended a formal class. Although $92 \%$ of the group who received structured diabetes education reported instruction in diet, only $37 \%$ reported instruction in all six of the content areas determined to be of major importance.

In another study ${ }^{7}$ based on prevalence data, only $3 \%$ to $4 \%$ of people with diabetes in the state of Washington attended diabetes education programs in 1982. In a follow-up survey of patients $(n=64)$ and physicians $(n=228)$ in that state, $66 \%$ of the patients were aware of local education programs, but only $38 \%$ had attended a program. The most frequent reason cited for nonattendance was that patients felt they were already knowledgeable about diabetes. Among physicians, $91 \%(n=208)$ indicated that they knew about the programs, although only $44 \%$ routinely referred their patients and $20 \%$ did not refer at all. Most physicians referred patients with

From the University of Michigan Medical School, Michigan Diabetes Research and Training Center, Towsley Center for Continuing Medical Education, Ann Arbor, Michigan.

This study was supported by the National Institutes of Health Grant No. 5P60DK20572, and by the National Institute of Diabetes, Digestive, and Kidney Diseases.

Correspondence to Robert M. Anderson, EdD, University of Michigan Medical School, Room G-1 116, Box 0201, Towsley Center for Continuing Medical Education, Ann Arbor, MI 48109-0201.

Reprint requests to The Diabetes Educator, 367 West Chicago Avenue, Chicago, IL 60610. 
insulin-dependent diabetes mellitus (IDDM) or non-insulindependent diabetes mellitus (NIDDM), however, 19\% referred only patients with special circumstances (eg, new diagnosis). ${ }^{7}$ A target goal specified in Healthy People $2000^{1}$ is that $40 \%$ of all people with chronic and disabling conditions receive patient education, and that $75 \%$ of all patients with diabetes receive diabetes education.

Because not all patients receive diabetes education, attempts have been made to determine the type of patient most likely to receive education. One study ${ }^{8}$ found that IDDM patients were more likely to have received instruction than NIDDM patients ( $72 \%$ vs $64 \%$ ). Another study ${ }^{9}$ reported that nonattenders were less educated, had lower incomes, were younger, and reported more barriers to self-care compared with program attenders. In another study, ${ }^{10}$ patients who initiated contact with a diabetes education program were more likely to attend than those who were actively recruited. None of these studies involved randomly selected patients of community-based, primary care physicians.

This study was conducted to answer the following questions: 1) To what extent are patients under the active care of community physicians receiving diabetes patient education and nutritional counseling? 2) Are there differences in the educational rate of patients with different disease types and treatments? 3) Does the diabetes patient education being received by patients result in optimum levels of knowledge? and 4) Has the proportion of patients (described in question 1) receiving diabetes patient education changed over the past 10 years?

\section{Design and Methods}

The majority of this study was conducted in 1991 on a randomly selected sample of communities, physicians, and people with diabetes throughout Michigan. The communities were selected and previously studied in 1981." A random selection of physicians and patients was carried out in 1981 and again in 1991. Two types of communities were defined (large and small) based on community and hospital size, and the patient care services available in those communities for persons with diabetes. Thirteen communities met the criteria for large communities and 34 communities met the criteria for small communities. From these 47 communities, 4 large and 4 small communities were randomly selected for inclusion in this study.

The study design required random selection of 15 primary care physicians from the yellow pages of the telephone book for each of the four large communities and 5 primary care physicians for each of the four small communities. Primary care physicians were defined as general and family practitioners, diabetologists (because they often provide primary care to patients with diabetes), and internists. Pediatricians were deliberately excluded because their numbers (and the number of patients with diabetes cared for by them) would have been too small to be representative.

Obtaining the prescribed number of physicians was not always possible. Two small communities did not have the requisite number of primary care physicians, and some selected physicians declined to participate, requiring the selection of additional physicians in some communities. A total of 130 physicians were invited to participate; 68 physicians (including 4 diabetologists) from eight communities agreed (52\% response rate).

A significant problem was that the primary care physicians in this study did not have a systematic method for determining the number and identity of their patients with diabetes. Office records usually are not coded or organized according to the systems used by record departments in hospitals. The method we adopted for identifying patients was having the office receptionist keep track of the names of patients with diabetes seen over a 4-month period. From this list, the office staff randomly selected 15 patients, using a random numbers table. Confidentiality was protected by having the initial study correspondence with patients come from their physician's office. Patients were invited to participate by their physician through a letter that described the study. Those interested in participating returned a postcard to the Michigan Diabetes Research and Training Center (MDRTC), thus revealing their identities. Interested patients who returned postcards to the MDRTC were contacted and an interview date was arranged.

Of the 1017 patients who received letters of invitation, 517 agreed to participate in the study (51\% response rate). Of the 517 patients, 440 were studied; the remaining number of patients were in excess of the established quota of 7 patients per physician. All participating physician practices were asked to provide anonymous demographic data from their records for the randomly selected patients who declined to participate in the study. Patients who agreed to participate in the study were for the most part not different from patients who declined. There were no statistically significant $(P \leq .05)$ differences between the two groups of patients with respect to age, gender, type of diabetes, percent of ideal body weight, percent of patients using insulin, percent of patients using oral agents, the type of physician providing care, or the mean age of physicians. The only difference was that the patients who declined to participate in the study had diabetes of slightly shorter duration ( 7.4 vs 8.9 years, $\mathrm{P}=.02$ ) than the patients who were studied.

Data Collection Extensive data were collected about the 440 patients, their primary care physicians, and the healthcare delivery system in each of the communities. Patients provided information on demographics, medical history, diet history, personal habits, diabetes self-care practices, medical care, and psychosocial factors. Project staff assessed key physical findings such as height, weight, blood pressure, visual acuity, presence of amputations, and a sensory neurologic exam of the lower extremities. Blood and urine samples were obtained for analysis in MDRTC core laboratories. The Diabetes Care Profile ${ }^{12}$ was used to assess the current level of diabetes self-care and professional care received. Glycosylated hemoglobin blood values were determined using the Isolab Glyc-Affin GHb test kit. The range of normal values for this test is from $4.0 \%$ to $8.0 \%$.

A revised version of the Diabetes Knowledge Test ${ }^{13}$ was administered. The test had two components, a general test component (14 items) and an insulin component ( 9 items). The reliability of the revised test was determined prior to this study using 434 administrations of the general test and 196 administrations of the insulin test. The Cronbach alpha for the general test was 0.71 and for the insulin test was 0.76 . 
Table 1. Demographics

\begin{tabular}{|c|c|c|c|c|c|}
\hline Characteristics & & $\begin{array}{l}\text { Total Sample } \\
\qquad(N=440)\end{array}$ & $\begin{array}{c}\text { IDDM* } \\
(\mathrm{n}=47)\end{array}$ & $\begin{array}{c}\text { NIDDM } \\
\text { Using Insulin } \\
(\mathbf{n}=\mathbf{1 5 2})\end{array}$ & $\begin{array}{c}\text { NIDDM } \\
\text { Not Using Insulin } \\
(n=241)\end{array}$ \\
\hline Female $(\%)$ & ' & 54 & 62 & 51 & 55 \\
\hline Age, $y$ & , & & & & \\
\hline Mean (SD) & . & $61.0(12.9)$ & $43.8(14.0)$ & $63.3(10.4)$ & $63.0(11.5)$ \\
\hline \multicolumn{6}{|c|}{ Duration of diabetes, $y$} \\
\hline Caucasian (\%) & & 92 & 98 & 88 & 93 \\
\hline Married (\%) & & 71 & 66 & 73 & 70 \\
\hline $\begin{array}{l}\text { Completed } 12 \text { y o } \\
\text { schooling }(\%)\end{array}$ & of formal & 71 & 98 & 65 & 70 \\
\hline \multicolumn{6}{|c|}{ Percent of ideal body weight } \\
\hline
\end{tabular}

Table 2. Diabetes Education History

\begin{tabular}{|c|c|c|c|c|}
\hline Category & $(n=438 *)$ & $(n=47)$ & $(n=151)$ & $(n=240)$ \\
\hline $\begin{array}{c}\text { Patients answering yes to the question, "Have } \\
\text { you received patient education?" }(\%)\end{array}$ & 58 & 89 & 74. & 42 \\
\hline \multicolumn{5}{|l|}{ Time since most recent education, $y$} \\
\hline Mean (SD) & $4.15(4.37)$ & $5.19(4.38)$ & $4.63(4.94)$ & $3.24(3.50)$ \\
\hline
\end{tabular}

Ten questions on the general test concerned blood sugar and diet, and four questions dealt with complications. The insulin test component was administered only to patients using insulin in the treatment of their diabetes.

Statistical Analysis Differences between the knowledge test scores and the glycosylated hemoglobin $(\mathrm{GHb})$ levels of patients who received diabetes education and patients who did not receive education were determined for the entire population and by types of diabetes, using the Student's $t$-test. Patients rated their understanding of 10 diabetes areas on a 5-point scale ( $1=$ Poor to $5=$ Excellent). An average then was determined for each patient. Patients whose average was from 1 to 3 were assigned to the diabetes-understanding level of "Poor to Fair." Patients whose average was greater than 3 were assigned to the "Good to Excellent" level. Differences between the scores of patients with a "Poor to Fair" understanding and a "Good to Excellent" understanding on the general knowledge test were determined using the Student's $t$-test.

Differences in the percentage of patients who reported receiving diabetes education in 1981 and 1991 also were examined using Pearson Chi-square tests. Differences in the percent of patients who had received diabetes education in the last 2 years also were determined using Pearson Chi- square tests. These differences were determined for the entire population and by type of diabetes.

\section{Results}

The majority of the patients in the sample were NIDDM patients not using insulin (55\%), followed by NIDDM patients using insulin (34\%), and IDDM patients (11\%). The sample was predominantly white $(92 \%)$ and married $(71 \%)$. IDDM patients were younger, had a longer duration of diabetes, and had more formal education than the NIDDM patients (Table 1). The patient groups most likely to ever have received some diabetes education were IDDM patients $(89 \%)$ and NIDDM patients using insulin (74\%). Less than half ( $42 \%$ ) of the NIDDM patients not using insulin had ever received diabetes education.

Follow-up questions and clarification by interviewers made it clear to respondents that the question about diabetes education referred to formal patient education as opposed to information provided by a physician during a routine office visit. The average time since these patients had received diabetes education was 4 years, with NIDDM patients not using insulin having the most recent education (3.24 years) and IDDM patients having the least recent education (5.19 years) (Table 2 ). Recency of education appears related to duration of diabetes (ie, patients with the shortest duration had the most recent education) (Table 1). 
Table 3. Education by a Dietitian

\begin{tabular}{|c|c|c|c|c|}
\hline Category & $\begin{array}{l}\text { Total Sample } \\
\qquad\left(n=438^{*}\right)\end{array}$ & $\begin{array}{l}\text { IDDM } \\
(n=47)\end{array}$ & $\begin{array}{c}\text { NIDDM } \\
\text { Using Insulin } \\
(n=151)\end{array}$ & $\begin{array}{l}\text { NIDDM } \\
\text { Not Using Insulin } \\
(\mathbf{n = 2 4 0 )}\end{array}$ \\
\hline Referted to dietitian (\%) & 63 & 85 & 74 & 53 \\
\hline Patients who consulted a dietitian (\%) & 66 & 89 & 80 & 54 \\
\hline \multicolumn{5}{|l|}{ Time since last visit to dietitian, $y$} \\
\hline Mean $(S D)$ & $4.04(4.38)$ & $5.02(4.92)$ & $3.95(4.25)$ & $3.80(4.32)$ \\
\hline
\end{tabular}

Table 4. Amount of Diabetes Education Received/Desired

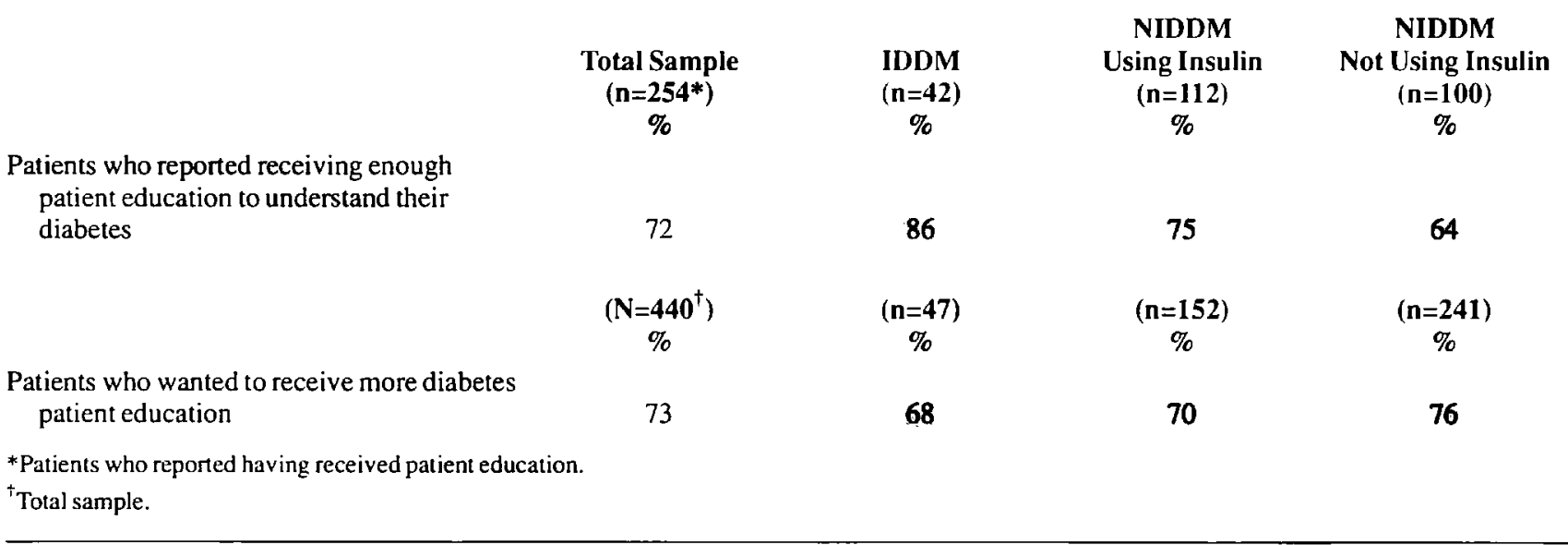

Table 5. Overall and Specific Scores on General Knowledge Test by Type of Diabetes

Overall score on general knowledge test

Score on the ten items about blood sugar and diet

Score on the four items about complications

Score on the insulin test

\begin{tabular}{|c|}
\hline $\begin{array}{c}\text { Total Sample } \\
\left(n=421^{*}\right) \\
\% \text { Correct } \\
\text { Mean (SD) }\end{array}$ \\
\hline $66(19)$ \\
\hline $58(21)$ \\
\hline $86(23)$ \\
\hline $56(25)^{\dagger}$ \\
\hline
\end{tabular}

*Total sample is less than 440 because not every patient answered every question.

†'Insulin-using patients only.

\begin{tabular}{|c|c|c|}
\hline $\begin{array}{c}\text { IDDM } \\
(n=47) \\
\% \text { Correct } \\
\text { Mean (SD) }\end{array}$ & $\begin{array}{c}\text { NIDDM } \\
\text { Using Insulin } \\
\text { (n=149) } \\
\% \text { Correct } \\
\text { Mean (SD) }\end{array}$ & $\begin{array}{c}\text { NIDDM } \\
\text { Not Using Insulin } \\
\text { (n=225) } \\
\text { \% Correct } \\
\text { Mean (SD) }\end{array}$ \\
\hline $82(12)$ & $66(17)$ & $62(19)$ \\
\hline $76(15)$ & $58(19)$ & $54(21)$ \\
\hline $96(9)$ & $88(21)$ & $82(25)$ \\
\hline $74(23)$ & $51(23)$ & - \\
\hline
\end{tabular}

NIDDM patients not using insulin were the least likely to have been referred to a dietitian (53\%) and least likely to have seen a dietitian (54\%) (Table 3 ). The percentage of patients who reported seeing a dietitian was greater than the percentage of patients who reported being referred to a dietitian. The "time since last visit to dietitian" reported in Table 3 was similar to the "time since most recent education" reported in Table 2.

When asked if they had received enough diabetes education, $86 \%$ of the IDDM patients reported that they had received a sufficient amount, followed by NIDDM patients using insulin (75\%), and NIDDM patients not using insulin
(64\%). When asked if they wanted more diabetes education, $76 \%$ of the NIDDM patients not using insulin reported that they wanted more diabetes education, followed by NIDDM patients using insulin $(70 \%)$, and IDDM patients $(68 \%)$ (Table 4).

A basic test of general diabetes knowledge revealed that NIDDM patients not using insulin had the lowest average score ( $62 \%$ correct), NIDDM patients using insulin had a slightly higher average score $(66 \%$ correct), and IDDM patients had the highest score $(82 \%$ correct) (Table 5). The pattem was similar for a subtest about insulin use, with IDDM patients scoring better than NIDDM patients using 
Table 6. A Comparison of Scores on General Knowledge Test by Type of Diabetes for Patients Who Received or Did Not Receive Diabetes Education

\begin{tabular}{|c|c|c|c|c|}
\hline . & $\begin{array}{c}\text { Total Sample } \\
\text { \% Correct } \\
\text { Mean (SD) }\end{array}$ & $\begin{array}{c}\text { IDDM } \\
\% \text { Correct } \\
\text { Mean (SD) }\end{array}$ & $\begin{array}{c}\text { NIDDM } \\
\text { Using Insulin } \\
\text { \% Correct } \\
\text { Mean (SD) }\end{array}$ & $\begin{array}{c}\text { NIDDM } \\
\text { Not Using Insulin } \\
\% \text { Correct } \\
\text { Mean (SD) }\end{array}$ \\
\hline $\begin{array}{l}\text { Score for patients who received } \\
\text { diabetes education }\end{array}$ & $\begin{array}{c}(n=252) \\
70(18)\end{array}$ & $\begin{array}{l}(n=45) \\
81(12)\end{array}$ & $\begin{array}{c}(n=111) \\
67(18)\end{array}$ & $\begin{array}{l}(n=99) \\
68(18)\end{array}$ \\
\hline $\begin{array}{l}\text { Score for patients who did not } \\
\text { receive diabetes education }\end{array}$ & $\begin{array}{l}(n=167) \\
60(18)^{*}\end{array}$ & $\begin{array}{c}(n=5) \\
84(15)^{\dagger}\end{array}$ & $\begin{array}{l}(\mathrm{n}=37) \\
64(13)^{\dagger}\end{array}$ & $\begin{array}{l}(n=125) \\
58(18)^{*}\end{array}$ \\
\hline
\end{tabular}

*Difference $P<.01$.

${ }^{\dagger}$ No difference.

Table 7. A Comparison of Scores on General Knowledge Test by Self-Reported Understanding of Diabetes*

\begin{tabular}{|c|c|c|c|c|}
\hline Self-Reported Understanding of Diabetes & $\begin{array}{c}\text { Total Sample } \\
(\mathrm{n}=252) \\
\% \text { Correct } \\
\text { Mean (SD) }\end{array}$ & $\begin{array}{c}\text { IDDM } \\
(\mathbf{n}=45) \\
\% \text { Correct } \\
\text { Mean (SD) }\end{array}$ & $\begin{array}{c}\text { NIDDM } \\
\text { Using Insulin } \\
(n=111) \\
\% \text { Correct } \\
\text { Mean (SD) }\end{array}$ & $\begin{array}{c}\text { NIDDM } \\
\text { Not Using Insulin } \\
\text { (n=99) } \\
\% \text { Correct } \\
\text { Mean (SD) }\end{array}$ \\
\hline Good to Excellent & $74(16)$ & $8(12)$ & $69(17)$ & $74(16)$ \\
\hline Poor to Fair & $66(18)^{\dagger}$ & $79(13)^{\ddagger}$ & $66(19)^{\ddagger}$ & $65(18)^{\$}$ \\
\hline
\end{tabular}

Table 8. A Comparison of Diabetes Education, 1981 vs 1991

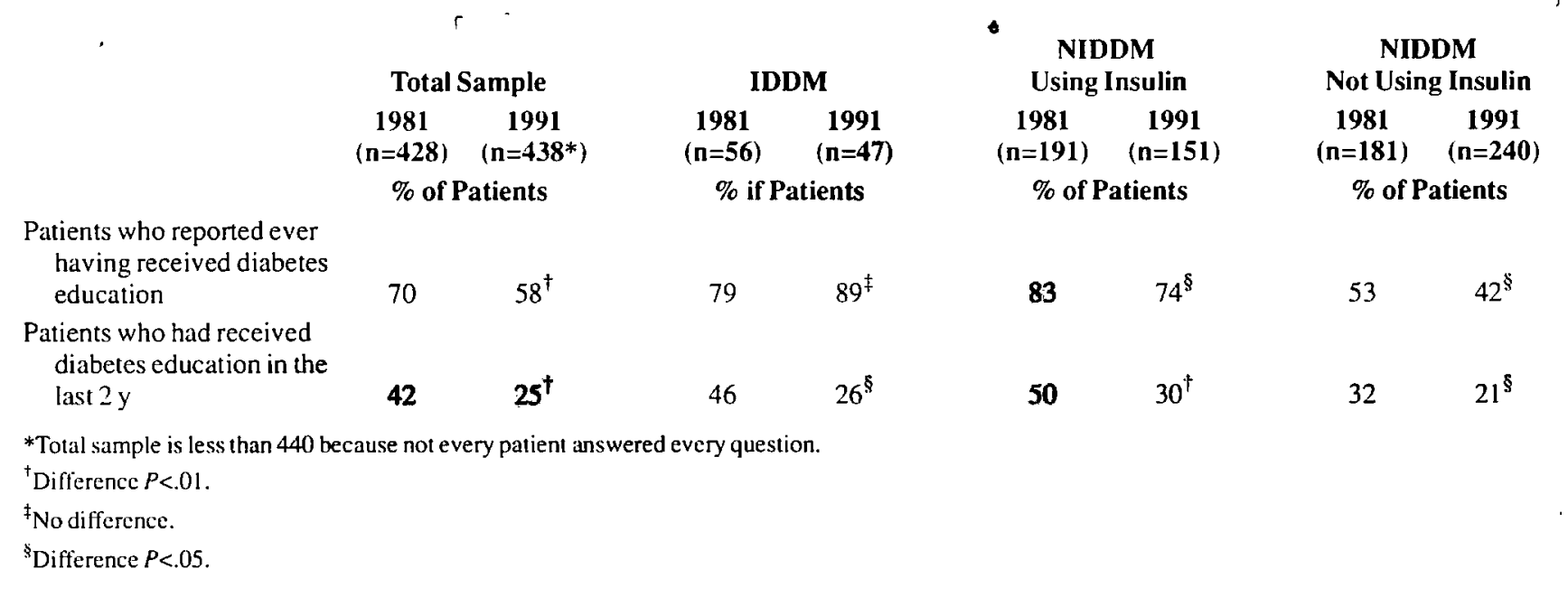

insulin (74\% vs 51\%) (Table 5). Among NIDDM patients not using insulin, those who had received diabetes education scored higher on the knowledge test than patients who had not received education (Table 6). There were no differences in the glycosylated hemoglobin levels. A difference between the knowledge test scores among patients who reported a "Good to Excellent" understanding of diabetes versus a
"Poor to Fair" understanding was found only among NIDDM patients not using insulin (Table 7).

The percentage of patients who reported having received diabetes education has decreased in the past 10 years, particularly among NIDDM patients (Table 8). In this study, $74 \%$ of NIDDM patients using insulin reported having received diabetes education compared with $83 \%$ in 1981. For 
NIDDM patients not using insulin, $42 \%$ of the patients in this study reported having received some diabetes education compared with $53 \%$ in 1981 . In addition, the percentage of both IDDM and NIDDM patients who reported having received diabetes education within the past 2 years was lower in this study than in 1981 (Table 8).

\section{Discussion}

Only $58 \%$ of this sample reported ever having received diabetes patient education, with the lowest percentage reported among NIDDM patients not using insulin. Although diabetes patient education is an integral part of comprehensive care and is recommended for all patients with diabetes, a significant number of patients are not receiving any education. Furthermore. patients not being treated with insulin are the least well served in terms of patient education. This finding is consistent with our experience working in the communities in this study. NIDDM that is not treated with insulin is not viewed as a serious disease by many physicians and consequently, by many patients. These patients tend to be relatively asymptomatic until they develop either the complications of diabetes or persistent hyperglycemia that often results in the initiation of insulin therapy. Treatment with insulin causes both physicians and patients to view diabetes as a more serious disease and is associated with a significant increase in referrals for diabetes education.

This pattem also was seen in referrals to a dietitian. Only $66 \%$ of the sample had ever seen a dietitian, and only $54 \%$ of the NIDDM patients not using insulin had seen a dietitian, even though some of the patients in this group supposedly were "diet-controlled." Over half of the patients who had never seen a dietitian indicated that they were never referred to a dietitian. Also, $22 \%$ of the patients indicated that they did not think education by a dietitian was important, and $27 \%$ did not know they were supposed to receive this type of education. Finally, 38\% of the patients indicated that they received their diet information from a physician. Given that the average amount of time that patients spend being educated during physician visits is about 12 minutes, ${ }^{17}$ the quantity and quality of nutrition education by physicians is questionable.

The majority $(72 \%)$ of the patients studied believed that they had received enough patient education to understand their diabetes. although a similar majority (73\%) also wanted to receive additional diabetes patient education. The average performance of this sample of patients on a basic diabetes knowledge test (overall score, $66 \%$ correct), however, indicates that their desire to receive additional education is more consistent with their actual level of knowledge than their perception that they had received enough diabetes education. IDDM patients scored highest on knowledge tests although they still missed some items basic to the management of diabetes. The knowledge test scores of the NIDDM patients were fair, although NIDDM patients not using insulin who had received education scored better than their counterparts who did not.

A positive relationship was identified between the patients' scores on the knowledge test and their self-reported understanding of diabetes. However, while significant for the overall sample, this relationship was influenced considerably by NIDDM patients not using insulin. Although pa- tients who rated their self-understanding as "Good to Excellent" scored higher on this basic knowledge test, their scores did not quite justify the perception that their understanding of diabetes was "Good to Excellent."

A comparison of the 1981 data" with the 1991 data reveals a decrease in the number of patients receiving diabetes patient education, from $70 \%$ to $58 \%$, mainly among NIDDM patients. This decrease is most likely related to the shift from inpatient to outpatient diabetes education. In the past, diabetes education was primarily an inpatient service for hospitalized patients. ${ }^{15}$ This service was provided by hospital staff members and generally paid for as part of nursing or bed costs. Since the advent of prospective payment for hospital services. hospital admissions and lengths-of-stay have decreased. and acuity levels have increased among persons with diabetes. ${ }^{16}$ Hospital ized patients frequently are too ill to learn and hospitals are unlikely to delay discharge for the sake of patient education..$^{15}$ Also, patients are started on insulin in the outpatient setting much more frequently. As a result, diabetes education has shifted from an inpatient service to one provided primarily for outpatients. Because outpatient diabetes education often is not reimbursed and because outpatients are not a captive audience the way inpatients are, fewer patients are receiving education.

\section{Study Limitations}

The response rate of $52 \%$ among the physicians who were invited to participate in this study is a limitation. Generally a higher response rate is desirable to be able to generalize confidently about the population in question. However, since this study found essentially negative results (ie, the quantity of diabetes patient education was inadequate), generalizability should not be a major concern. The lower-than-ideal response rate would be a threat to the validity of the study only if the physicians who declined to participate in this study were providing significantly better diabetes care than their colleagues who did participate. In such a case the results in this study would be biased toward negative results. Although this finding is possible, it is unlikely, because one would expect the physicians who were most confident and comfortable about their level of diabetes care to be most willing to participate in the study. Therefore, the findings probably are conservative because the physicians who did not participate in the study may have been providing less comprehensive diabetes care than those who did participate.

Another potential limitation is the response rate for patients, although this concern is offset largely by the fact that the patients who declined to be studied were similar to the study patients. The participation rate for patients decreased substantially from 1981 to 1991 . which is consistent with our experience that people generally are less willing to participate in research studies today than they were in past years. This disinclination to participate in studies of all kinds poses a serious concern for investigators involved in clinical research.

\section{Summary and Recommendations}

Diabetes is a chronic disease in which the patient provides over $95 \%$ of the routine daily care. Much of that care involves the application of sometimes complex self-care technology and the alteration of deeply imbedded lifestyle 
behaviors related to diet and physical activity. Diabetes education must be ongoing if it is to help patients develop and sustain the knowledge, skills, and lifestyle changes necessary for effective diabetes self-management. Diabetes education needs to be as much a part of ongoing diabetes care as physician visits. Investigators studying the problem of obesity and long-term weight loss have reached similar conclusions. ${ }^{17.18}$ Many of the problems identified in this study are symptomatic of the attempt to treat a chronic disease in a system designed for the treatment of acute conditions. Such a system does not value or emphasize preventive medicine, health education, social support, and lifestyle modification, which are the comerstones of modem diabetes care. The situation will probably not improve significantly until there are major changes in the healthcare system that allow for a more appropriate response to chronic diseases such as diabetes.

\section{References}

1. Healthy People 2000: national health promotion and disease prevention objectives. Washington, DC: US Government Printing Office, Public Health Service, 1990; DHHS publication no. (PHS) $91-50212$.

2. American Diabetes Association. Standards of medical care for patients with diabetes mellitus. Diabetes Care 1992;15(suppl 2):10-13.

3. Brown SA. Effects of educational interventions and outcomes in diabetic adults: a meta-analysis revisited. Patient Educ Couns 1990;16: 189-215.

4. Brown SA. Studies of educational interventions in diabetes care: a meta-analysis of findings. Nur Res 1988:37:223-30.

5. Padgett D, Mumford E, Haynes M, Carter R. Meta-analyses of the affects of educational and psychosocial interventions on management of diabetes mellitus. J Clin Epidemiol 1988;41:1007-30.
6. Halpern M. The impact of diabetes education in Michigan. Diabetes 1989;38(suppl 2):151A.

7. Chapko MK, Norman JL, Bell-Hart M, Nagusky D. Connell FA. Increasing the utilization of outpatient diabetes education programs. Diabetes Educ 1987:13:116-18.

8. Jenny $\mathrm{J}$. Differences in adaptation to diabetes between insulindependent and non-insulin-dependent patients: implications for patient education. Patient Educ Couns 1986;8:39-50.

9. Irvine AA, Mitchell CM. Impact of community-based diabetes education on program attenders and nonattenders. Diabetes Educ 1992;18(1): 29-33.

10. Glasgow RE, Toobert DJ, Hampson SE. Participation in outpatient diabetes education programs: how many patients take part and how representative are they? Diabetes Educ 1991;17(5):376-80.

11. Anderson RM, Hess GE, Davis WK. Hiss RG. Community diabetes care in the 1980s. Diabetes Care 1988;11:519-26.

12. Hess GE, Davis WK, Harrison RV. A diabetes psychosocial profile. Diabetes Educ 1986; 12:135-40.

13. Hess GE, Davis WK. The validation of a diabetes patient knowledge test. Diabetes Care 1983;6:591-96.

14. Hiss RG. Frey ML. Davis WK. Diabetes patient education in the office setting. Diabetes Educ 1986;12:281-85.

15. Schwarz R. Third-party reimbursement coverage for diabetes care. The prospective payment system: implications for diabetes patient education. Diabetes Educ 1985; 11 (2):70.

16. Weinberger M, Ault KA, Vinicor F. Prospective reimbursement and diabetes mellitus impact upon glycemic control and utilization of health services. Med Care 1988:26:77-83.

17. Wing RR. Behavioral treatment of obesity: its application to type II diabetes. Diabetes Care 1993;16:193-99.

18. Perri MG, Sears SF, Clark JE. Strategies for improving maintenance of weight loss: toward a continuous care model of obesity management. Diabetes Care 1993:16:200-9. 